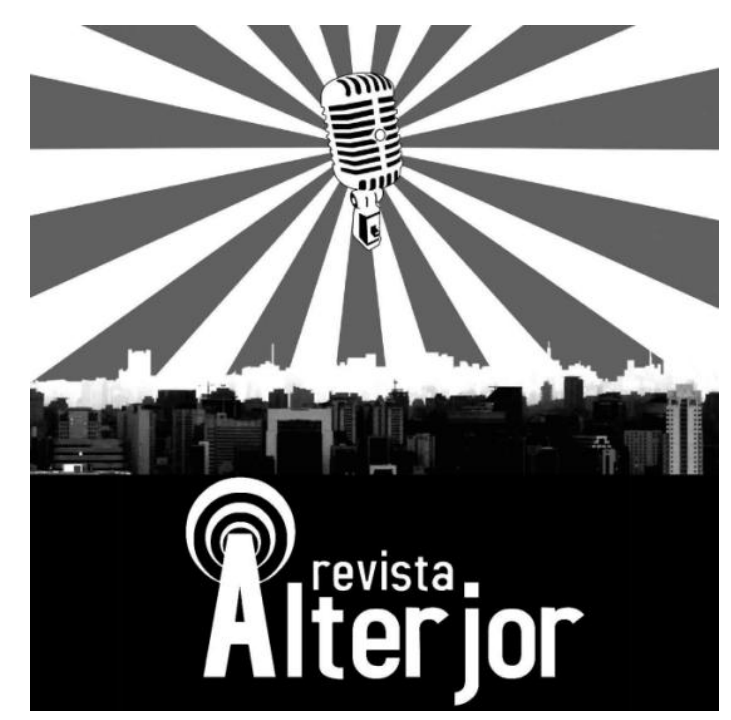

$\underline{\text { ENSAIO }}$

\title{
DIÁRIOS DE EMERGÊNCIA COVID19: LITERATURA PARA ENFRENTAR O CONFINAMENTO
}

\author{
Miriane da Costa Peregrino ${ }^{1}$
}

\begin{abstract}
RESUMO: Apresentamos aqui a iniciativa Diários de Emergência Covid-19 do Jornal Literatura Comunica, que reúne 63 testemunhos de brasileiros em diferentes regiões do Brasil e do exterior durante o isolamento social. Os jornais foram publicados em quatro números ao longo de 2020: "Rio de Janeiro", " Brasil, Norte a Sul", "Brasileiros no Exterior" e "E a Segunda Onda?". Entendendo que a Literatura é uma forma de reelaboração da realidade, a iniciativa parte do exemplo dos escritos de isolamento de Anne Frank, Lima Barreto e Carolina de Jesus.
\end{abstract}

PALAVRAS-CHAVE: Diários. Covid-19. Brasileiros no exterior. Memórias. Isolamento Social.

ABSTRACT: Here we present the initiative Diaries of Emergency Covid-19 of the Jornal Literatura Comunica, which brings together 63 testimonials from Brazilians in different regions of Brazil and abroad during social isolation. The newspapers were published in 4 issues throughout 2020: "Rio de Janeiro", "Brazil, North to South", "Brazilians Abroad" and "What about the Second Wave?". Understanding that Literature is a reworking of reality, the initiative starts from examples of isolation writings by Anne Frank, Lima Barreto and Carolina de Jesus.

KEYWORDS: Diaries. Covid-19. Brazilians Abroad. Memories. Social Isolation.

\footnotetext{
${ }^{1}$ Organizadora dos Diários de Emergência Covid19 publicados pelo Jornal Literatura Comunica. Desde 2013 atua em coletivos de educação e comunicação populares, tendo reportagens publicadas no RioOnWatch, Agência de Notícias das Favelas e outros. É doutora em Ciência da Literatura (UFRJ, Brasil) com estágio de pesquisa na Universidade Agostinho Neto (UAN, Angola). Atualmente, é pesquisadora visitante na Universidade de Colônia (Uni-Köln, Alemanha). E-mail: miriane.peregrino@gmail.com
}

Revista ALTERJOR

Grupo de Estudos Alterjor: Jornalismo Popular e Alternativo (ECA-USP)

Ano 10 Volume Ol Edição $23 \quad$ Janeiro-Julho de 202l

Avenida Professor Lúcio Martins Rodrig̉ues, 443, Cidade Universitária, São Paulo, CEP: 05508-020 


\section{INTRODUÇÃO}

Como produzir literatura na quarentena? Como dar sentido as frustrações, medos e incertezas que a suspensão do cotidiano devido, a ameaça do vírus, provocava? Foi o que me perguntei quando o governo alemão anunciou o fechamento das fronteiras por aqui. Aulas adiadas, congressos cancelados, fronteiras fechadas, surtos de pânico esvaziando prateleiras de supermercados da Marktplatz, em Mannheim, cidade alemã para onde vim há 11 meses.

Desde garota, a literatura sempre foi um refúgio para mim e quando o confinamento chegou, ela se tornou meu refúgio de novo. Lembrei de Lima Barreto (1881-1922) escrevendo "Diário do Hospício" enquanto era interno no Hospital Nacional dos Alienados, no Rio de Janeiro. Lembrei do "Diário de Anne Frank", relato da própria Anne Frank (1929-1945), uma menina alemã de família judia, sobre a perseguição aos judeus durante a Segunda Guerra Mundial. Lembrei do "Quarto de despejo: diário de uma favelada" de Carolina de Jesus (1914-1977) e suas narrativas sobre a favela do Canindé, em São Paulo.

Todos eram diários de confinamento: o confinamento no hospício, o confinamento de uma família judia num anexo secreto na tentativa de sobreviver a guerra e escapar do campo de concentração, o confinamento em um quarto de despejo, a favela, para onde a elite econômica empurra há mais de um século os mais pobres.

No entanto, mais do que literatura de testemunho, esses diários dão forma a uma literatura de urgência na qual a narrativa serve para enfrentar situações-limite: a situação-limite do confinamento, a situação-limite da segregação.

Para esses escritores narrar não era só uma forma de deixar registrado o cotidiano, era também uma forma de sobreviver, de resistir, e era também uma maneira de projetar futuro, de sonhar, de reelaborar a realidade.

Em "Diário do Hospício", Lima Barreto traçou as primeiras linhas de seu futuro romance "Cemitério dos vivos". Anne Frank contou em seu diário que usaria aquelas anotações para escrever um romance sobre o anexo secreto assim que a guerra acabasse. 


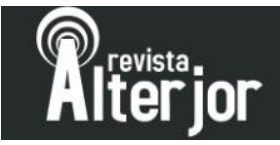

Carolina de Jesus anunciava no diário o seu sonho de conquistar a casa própria, o que ela realizaria e narraria no seu segundo livro "Casa de Alvenaria: diário de uma exfavelada".

Lima Barreto e Anne Frank, porém, tiveram seus sonhos interrompidos. Ele morreu aos 41 anos, deixando "Cemitério dos vivos" um romance inacabado. Ela foi separada de seu diário quando o anexo secreto foi descoberto e todos os moradores enviados para o campo de concentração, onde Anne morreria alguns meses depois.

Pensar nesses diários fez surgir a ideia de organizar um número especial sobre diários na quarentena no jornal do projeto Literatura Comunica! que lancei no Rio de Janeiro ano passado com um grupo de comunicadores populares.

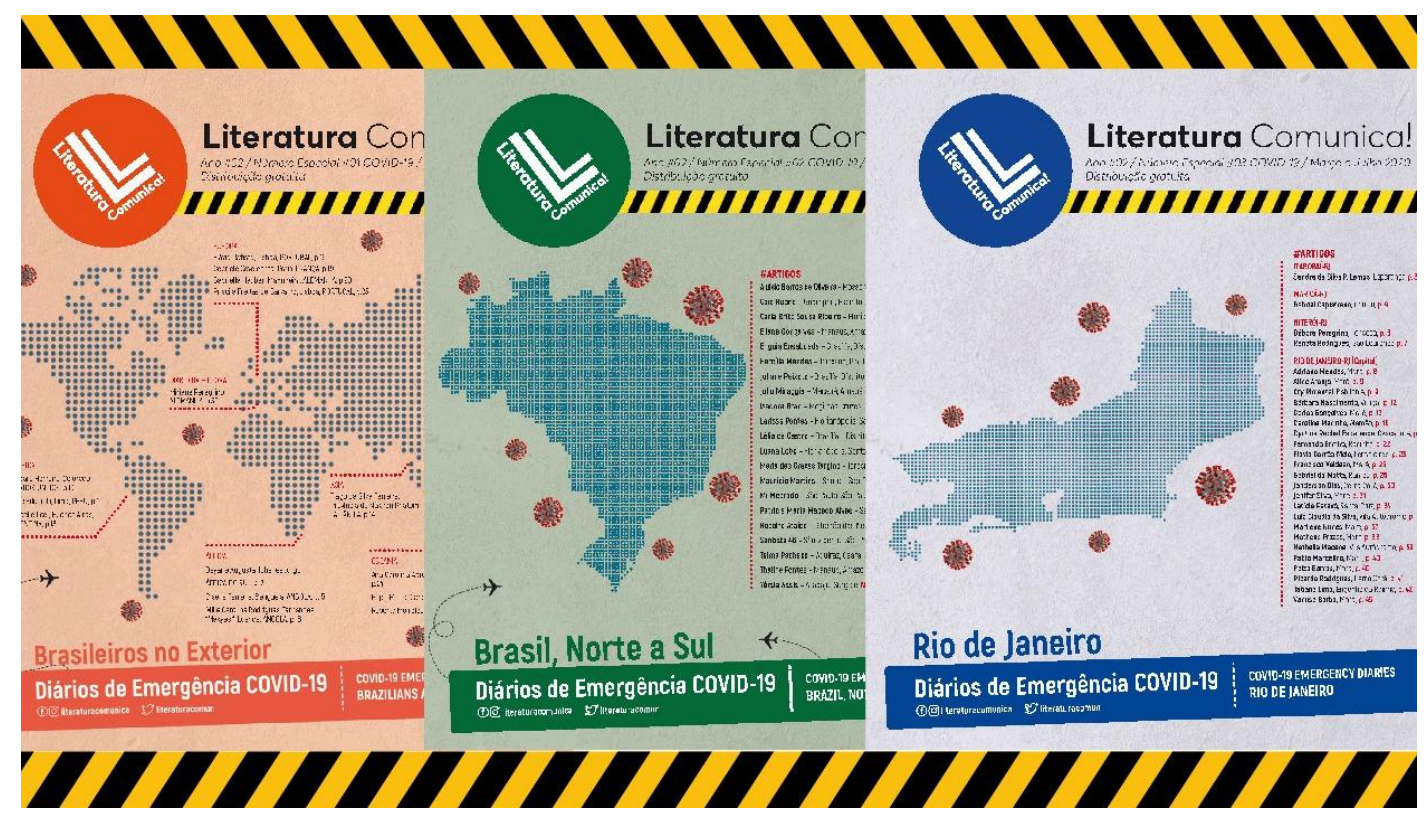

Capas dos três números dos Diários de Emergência Covid19 (março a julho). O quarto número "E a Segunda Onda?" foi publicado em dezembro. Todos os jornais estão disponibilizados gratuitamente na plataforma digital issuu. Diagramação: Filipe Mendonça.

Em abril comecei a convidar brasileiras e brasileiros conhecidos e amigos para escreverem diários sobre o isolamento. Em maio, lancei uma chamada pública nas redes sociais do projeto e pessoas desconhecidas também enviaram seus textos. Em junho já tinha 60 textos para revisar. Anísio Borba fez os flyers de divulgação dos diários. A 


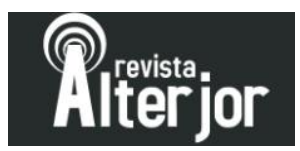

ideia era publicar trechos dos diários semanalmente até fechar a revisão e produção do jornal. Filipe Mendonça começou a diagramar a edição especial e em fins de julho lançamos os Diários de Emergência Covid19 em três números: "Brasileiros no Exterior", "Brasil, Norte a Sul" e "Rio de Janeiro".

Quando tive a ideia dos diários em abril achava que até lançarmos o jornal a pandemia já teria passado. Engano. O Brasil se tornou um dos principais epicentros da Covid19 no mundo.

Alguns autores se dedicaram mesmo ao formato de diário, escrevendo quase todos os dias, outros adotaram o formato de uma carta, uma pediu para eu publicar um dos textos de seu blog. A edição tem também dois posts das redes sociais que li e me impactaram, fazendo-me entrar em contato com os autores e perguntar se poderia republica-los na edição especial do jornal Literatura Comunica.

O primeiro foi um conjunto de posts de Dayane Augusta, historiadora brasileira que tentava conseguir um voo de repatriamento da África do Sul para o Brasil. Durante cerca de dez dias, Dayane fez de suas redes sociais uma espécie de diário de repatriamento. O segundo texto foi de Ricardo Rodrigues, artista do Rio de Janeiro, que fez um post emocionado sobre a morte de um amigo de infância pela Covid19.

Uma semana antes, eu tinha convidado Ricardo para escrever um diário e ele tinha recusado o convite. Diante da perda do amigo para o vírus, Ricardo produziu uma literatura da urgência, através da palavra reelaborou a dor da perda. Foi aí que percebi que os diários viriam da emergência da palavra. 

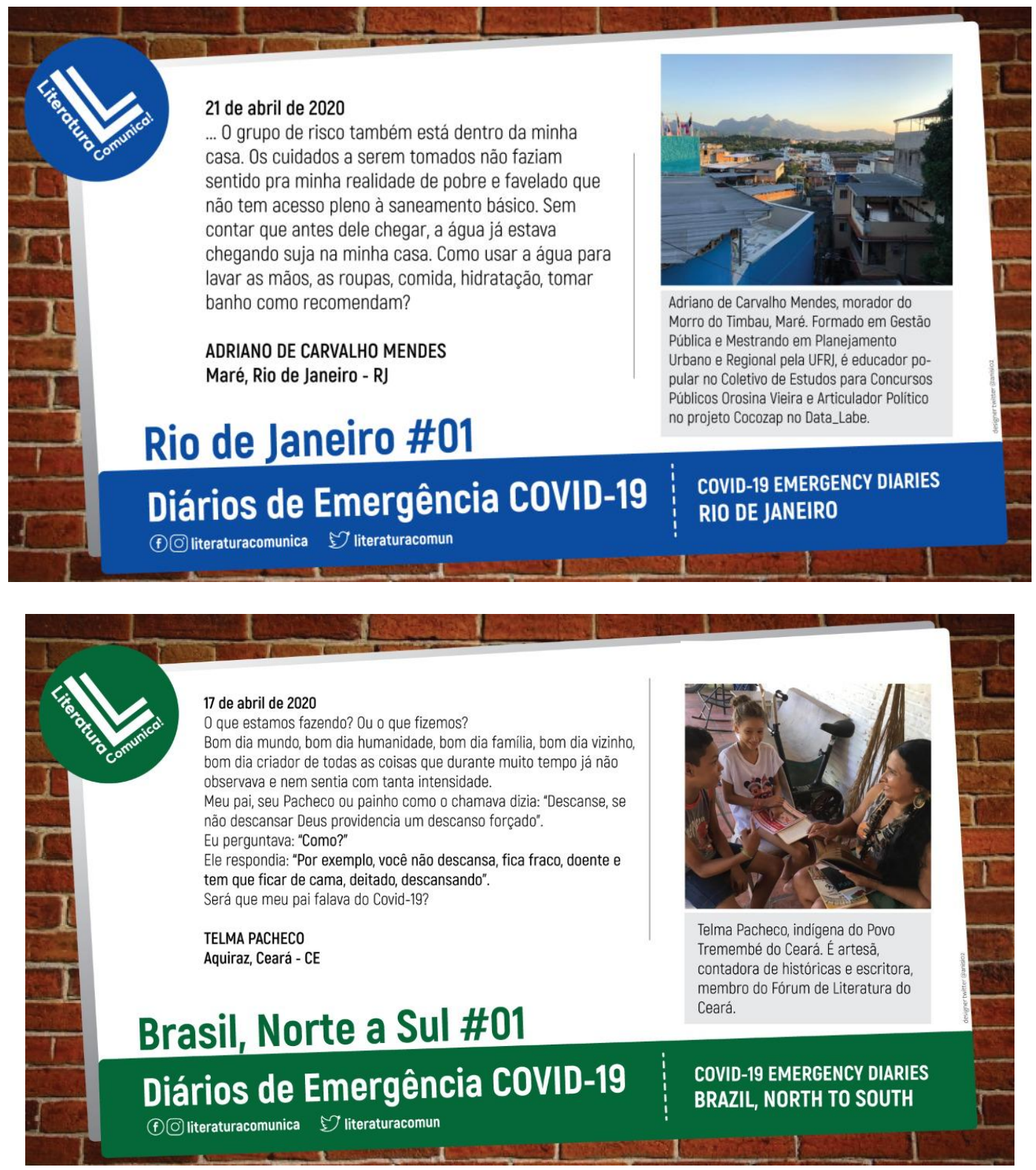


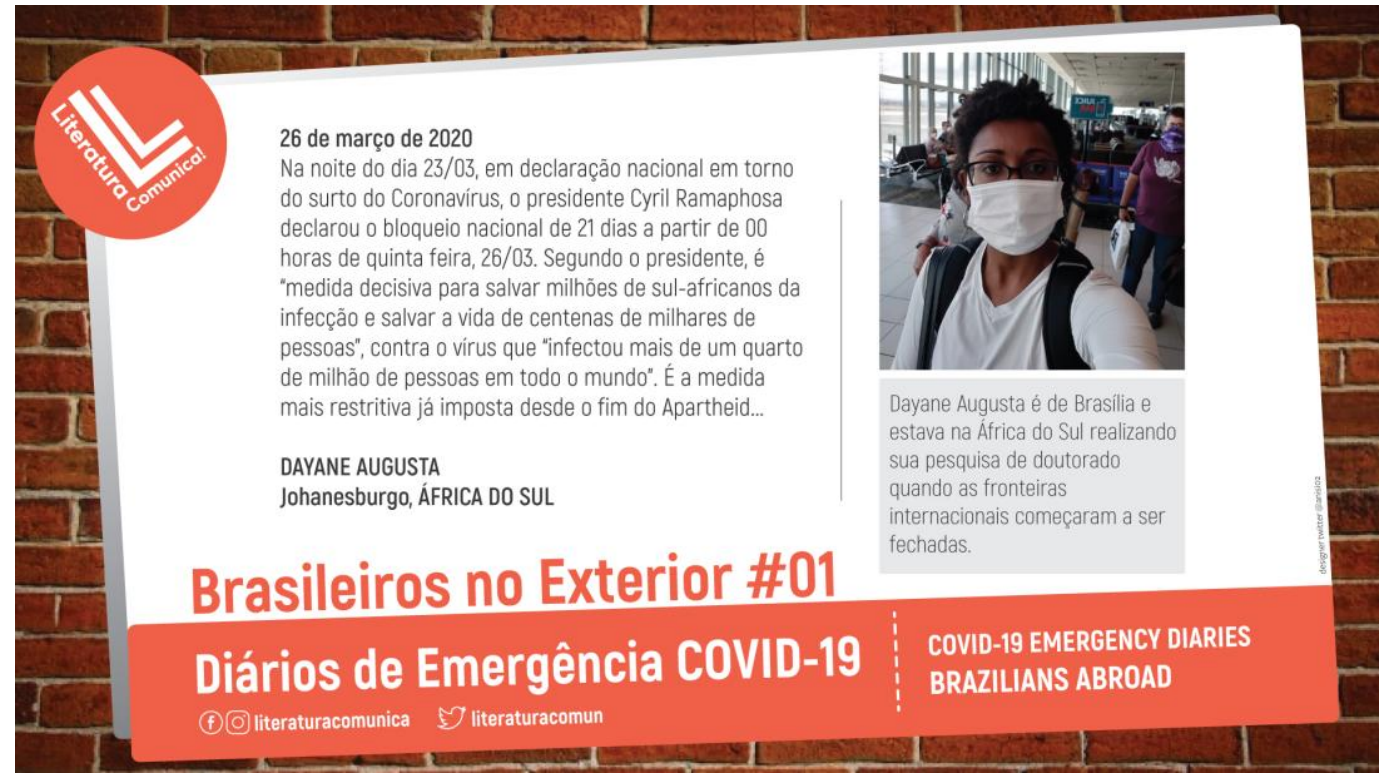

Flyers de divulgação dos Diários de Emergência COVID-19. Arte: Anísio Borba.

Trechos destacados:

20 de março de 2020

Uma amiga que esteve ontem comigo, encontra-se internada. É a Covid-19, suspeitam e dizem coisas horríveis sobre a doença. O mundo conversa nas redes sociais.

\section{ALUÍSIO BARRAOS DE OLIVEIRA}

\section{Mossoró, Rio Grande do Norte}

\section{3 de abril de 2020}

Levava uma vida tranquila em Lima (capital). Tranquilidade que teve fim numa tarde de domingo (15 de março), após o presidente Martin Vizcarra declarar quarentena e fechar as fronteiras do país para conter o avanço da pandemia.

\section{FILIPE EDUARDO}

\section{Lima, PERU}




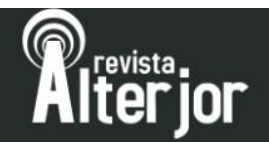

\section{5 de abril de 2020}

Uma incerteza e uma tensão grandes. As tias das bancas de frutas e verduras, onde compro, choram porque não podem ficar em casa, senão morrem de fome. Tem sido difícil saber notícias do meu país, em completo abandono. As favelas, as periferias, os subúrbios... O nosso povo preto, pobre, como sempre na frente das trincheiras, são os primeiros a morrer.

\section{MILLE CAROLINE RODRIGUES FERNANDES 'MAKYESI'}

\section{Luanda, ANGOLA}

\section{0 de abril de 2020}

Se há seis meses um viajante do tempo tivesse me contado que ia acontecer uma pandemia e um confinamento global, com fronteiras fechadas, companhias aéreas paradas e quase todas as atividades paralisadas, eu não sei como eu imaginaria que seria minha rotina nessa situação.

Mas decididamente não imaginaria como tem sido.

\section{FLÁVIA BATISTA}

\section{Lisboa, PORTUGAL}

\section{6 de abril de 2020}

Eu perdi um Amigo hoje em consequência dessa praga de corona vírus. Moleque bom, trabalhador, não era muito de ficar na rua. De casa pro trabalho, do trabalho pra casa. Devia ter uns 42 anos... Tô usando a máscara, alguns riem, dizem ser bobeira, outros pedem uma e perguntam onde eu comprei. Vai ser de uso obrigatório em breve...

\section{RICARDO RODRIGUES}

Cerro Corá, Rio de Janeiro - RJ

2 de maio de 2020 


\section{Ritieior}

\#ficaemcasa é para todos? Que tal \#ficaemcasa cozinhe sua própria comida e pare de expor a humanidade com seus pedidos de entrega? "mas estou ajudando com a manutenção da economia dessa pessoa", com a gorjeta que você nunca deu antes e não dá agora?

\section{FERNANDO ERMIRO}

\section{Rocinha, Rio de Janeiro-RJ}

\section{6 de maio de 2020}

“Papai, papai, brinca comigo?". O pedido do meu filho Bento, de quatro anos, é comum nos meus finais de semana de folga, quando ele também não está na escola. Mas não é o caso. O chamado insistente, embora doce, é no meio do meu expediente. Dentro de casa.

\section{MAURÍCIO MARTINS}

\section{Santos, São Paulo}

\section{2 de maio de 2020}

Ao contrário do Canadá e Irlanda, que deram suporte aos estudantes internacionais, o Primeiro Ministro da Austrália disse que não daria suporte e quem não tivesse condições de se manter aqui, que voltasse para o seu país. Saúde mental foi para o espaço, o sono que antes era regulado deu lugar a insônia, a alegria deu lugar a tristeza, a certeza foi tomada pela incerteza e insegurança. Se antes eu planejava a minha vida, agora não era mais possível. Tive que aprender a viver um dia de cada vez.

\section{ROBERTA MEIRELES}

Sidney, AUSTRÁLIA

\section{2 de maio de 2020}

Assombro muitos (...) quando digo que estes longos 70 dias de enfrentamento à Covid19, nos quais me mantive totalmente só, pouco mudaram minha vida. Afinal, perdi a 
noção exata de há quantos anos vivo num mundo que constrói à parte por imposição da sociedade, que repudia sem palavras, de forma silenciosa, os que envelhecem.

\section{MARIA DAS GRAÇAS TARGINO}

\section{Teresina, Piauí}

\section{$20 / 06 / 2020$}

Vou aproveitar esse espaço para pedir que quem estiver lendo e puder de alguma forma ajudar a causa indígena, no Brasil, no seu estado, na sua cidade, faça!!!

\section{THALINE FONTES}

\section{Manaus, Amazonas}

\section{Rio 22-06:}

\section{A Revolução será literária}

Ele nos cedeu 100 livros infantis do seu acervo pessoal, para que revezássemos entre nossas crianças, desde esta data fundamos o nosso clube literário infantil Rosangela Marinho. Então, todos os meses, as cestas básicas que doamos para 100 famílias no Alemão, vão acompanhadas por livros infantis.

\section{CAROLINA MARINHO}

\section{Alemão, Rio de Janeiro-RJ}

2020

Nunca pensei que fosse viver momentos da minha vida como se estivesse inserido dentro de cenas de filme sobre pandemias. Com a cidade com seus comércios com as portas fechadas e com o esvaziamento nas ruas com o isolamento social gera todo um clima de suspense que para mim soa como assustador. Ainda não me acostumei.

\section{LUIZ CLAUDIO DA SILVA}

Vila Autódromo, Rio de Janeiro-RJ 


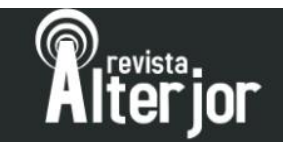

\section{0 de novembro}

Sétimo dia de apagão no Amapá. Agora à noite, a maioria dos bairros em Macapá estão sem energia. Foram registrados protestos como esses em diferentes bairros, bloqueando ruas. \#sosamapa

\section{JULIO MIRAGAIA}

\section{Macapá, Amapá}

13/12 - Em casa, com dor, e tentando passar o diário limpo. Conversei com a minha mãe hoje, ela disse que teve um sonho lindo com o meu tio que faleceu no meio do ano. Ela contou que ele chegava e dava um abraço nela, e os dois ficaram ali, num abraço longo.

\section{CYNTHIA RACHEL ESPERANÇA}

\section{Cascadura, Rio de Janeiro-RJ}

Esse emaranhado de narrativas, de tantas pessoas em lugares diversos, foi se formando uma comunidade afetiva e curativa dos medos da pandemia, da experiência do confinamento para mim (primeira a ler todos os textos) e creio que para os próprios autores e leitores, em geral, conforme os textos foram sendo publicados em flyers e no jornal.

Nossos Diários de Emergência Covid-19 surgem da necessidade de narrar que existe em cada um nós, da palavra que ganha corpo na tela de computador, texto ou vídeo nas redes sociais e mesmo naquele velho caderno de anotações à maneira de Lima Barreto, Anne Frank e Carolina de Jesus na primeira metade do século XX.

Tentei eu mesma dar continuidade ao diário que tinha iniciado no ano novo, em Colônia. Mas o que achei mais importante dos meus dias de isolamento foram os dias de produção do jornal, então, nomeei o meu relato de "diário da editora" para contar mais sobre o processo de organização dos diários.

Depois da publicação dos três primeiros números e diante da continuidade da pandemia, publicamos em dezembro o quarto número dos diários chamado "E a Segunda Onda?" reunindo alguns dos autores numa publicação mais compacta.

\section{Revista ALTERJOR}

Grupo de Estudos Alterjor:Jornalismo Popular e Alternativo (ECA-USP)

Ano 10 Volume Ol Edição 23 Janeiro-Junho de 2021 


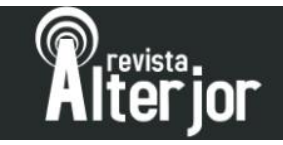

Todo o material está disponível gratuitamente nas plataformas digitais.

\section{Mais informações sobre os Diários de Emergência Covid19:}

Instagram e Facebook: @literaturacomunica

Twitter: @literaturacomun

Jornais gratuitos: https://issuu.com/literaturacomunica

Site: $\underline{w w w . l i t e r a t u r a c o m u n i c a . c o m . b r}$

\section{LEGENDAS}

Foto 1: Capas dos três números especiais Diários de Emergência Covid19. Todos os jornais estão disponibilizados gratuitamente na plataforma digital issuu. Diagramação: Filipe Mendonça.

Foto 2: Flyer de divulgação do diário de Dayane Augusta, Brasileiros no Exterior. Arte: Anísio Borba.

Foto 3: Flyer de divulgação do diário de Telma Pacheco, Brasil, Norte a Sul. Arte: Anísio Borba.

Foto 4: Flyer de divulgação do diário de Adriano Mendes, Rio de Janeiro. Arte: Anísio Borba. 